\title{
3 The Use of Advance Directives in the Context of Limited Resources for Healthcare
}

\author{
Ruth Horn, Ruud ter Meulen \\ Centre for Ethics in Medicine, University of Bristol, ruth.horn@bristol.ac.uk; \\ r.terMeulen@bristol.ac.uk
}

\begin{abstract}
Health and social care systems in the developed world are facing increasing concerns about the medicalization of dying. There are concerns not only that the costs of end-of-life medical care may become unsustainable but also that unbridled application of medical technology may lead to inappropriate end-of-life care. Older people in particular have an increased risk of dying in highly technical medical surroundings. Since the mid-1990s, the question has been raised whether the use of advance directives to refuse treatments might help to reduce the costs of care. Advance directives have the purpose of sustaining patient autonomy in cases where patients are no longer competent, particularly so as to prevent unwanted treatment or overtreatment. Would it then be ethically justifiable to promote them as instruments for cutting the costs of care or reallocating resources from acute to long-term care settings? Or would such a use of advance directives be tantamount to an abuse of patient self-determination? This chapter first provides an account of the cost-control and medical technology context, as well as the increasing difficulties of public health systems in sustaining appropriate levels of end-of-life care. We then review studies of the impact of advance directives on the costs of such care. Finally, we discuss the ethical acceptability of the use of advance directives in the context of cost control and equitable allocation of resources.
\end{abstract}

\subsection{The High Costs of Dying}

Since the nineteenth century, medical care has seen continuous technological advances enabling physicians to make a reliable diagnosis for all kinds of disease, to cure many diseases in a safe and effective manner, and to support public health measures such as infection control and screening for specific diseases. Technological advances allow diseases and other health problems that could not be cured in the past to be treated effectively today (Jones 2002). Medical technology is nowadays hugely admired, and there is a strong expectation that it will be able to heal all our diseases and even to extend our lives indefinitely. 
But there are concerns, firstly about the power of medical technologyparticularly, the power to put itself at the heart of medical care at the expense of other practices and moral values. Certainly in the final stages of life, there is a concern that medical technology takes control of the dying process, while the patient might be much better off in a hospice setting, for example. Instead of heroic measures to save and extend life, a hospice offers a caring environment in which pain is alleviated, personal relationships are established and meaning can be found. All too often, such caring practices have to give way because of expectations or fascination about what technology might be able to do to get the patient "back to life". As a result, patients often die in a hospitalized environment, surrounded by bleeping machines and by a family frightened by what is happening to their loved one and feeling out of control. The patients themselves have lost the sense of what is going on and have lost the capacity to make decisions about their care.

A second problem has to do with costs. Medical technology is usually expensive and is considered to be the most important factor in the rise of healthcare costs. Newhouse (1992) concludes that more than 50\% of the rise in healthcare costs in recent decades has been caused by technological change, "or what loosely might be called the march of science and the increased capabilities of medicine". According to Jones (2002), healthcare expenditures across the OECD increased between 1960 and 1997 from about $4 \%$ to about $8 \%$ of GDP on average. At least half, and most likely three quarters or more, of this change seems to be driven by medical technology. The majority of costs are incurred in the final year of life. Researchers in Manitoba, Canada, for example, found that $1.1 \%$ of the population consumed $21.3 \%$ of healthcare costs and that these costs arose in the final six months of life (Fassbender et al. 2009). In the US, just $10 \%$ of the 24 million Medicare beneficiaries who received inpatient or outpatient hospital care in 2009 accounted for $64 \%$ of the costs of the programme. Care associated with the end of life accounts for $10-12 \%$ of the overall US health budget and $27 \%$ of the Medicare budget (Lubitz and Riley 1993). Medicare provides access to medical care for people over 65 and for people with disabilities. As Callahan (2009: 1) points out, healthcare costs have increased annually by between $7 \%$ and $12 \%$ for many years and the rate is expected to remain at around $6-7 \%$. In 2007, $16.3 \%$ of US GDP was spent on healthcare, a figure expected to rise to $19.5 \%$ in 2017. Medicare's budget is projected to climb from $\$ 427$ billion in 2007 to $\$ 884$ billion in 2017. As Medicare accounts for a substantial part of the US health budget, the overall costs of care will rise correspondingly. According to Callahan (2009:2):

The projections are that the Medicare program will go bankrupt in 10 years or so, and the overall cost of health care will rise from $\$ 2.2$ trillion in 2007 to over $\$ 4$ trillion in the next decade or so, an astonishing jump.

The reasons why attempts to cut the costs seem to fail, point to increasing possibilities of technology able to treat always more pathologies, and to the increasing number of those who use these technologies (Callahan 2009: 23). 
Though Medicare does fund the treatment of older people (over 65), there is increasing evidence that the high costs of care in the final year of life cannot be attributed to age per se; rather, the costs of care are more related to proximity to death. People close to death have much higher health expenditures than those at the same age who survive (Miller et al. 2004). According to Zweifel et al. (1999), average healthcare expenditures are higher for elderly than for non-elderly persons not because of higher morbidity but because of higher mortality. Further evidence in support of the hypothesis that healthcare expenditures depend primarily on time to death rather than age is provided by McGrail et al. (2000) and Yang et al. (2003). Elderly persons consume much more healthcare in the last year of life no matter how old they are when they die. Research in the UK found a similar pattern for inpatient care: irrespective of age, patients tended to use most of their lifetime bed days in the year immediately before death (Dixon et al. 2004). The results of the UK study confirm that "the highest proportion of costs for acute care are incurred in the final years of life, no matter at which age this happens to be". According to the researchers, the "total costs of acute care are greater in elderly people simply because this age group makes up a larger proportion of dying people." As we will discuss in the following section, the benefits of high-cost acute care for this population are questionable, particularly with regard to quality of life and physical welfare in the sense of respecting patients' preferences. It is from this perspective that advance directives become relevant means to put technology on hold and to help patients take control of end-of-life decision-making, even if they are no longer able to express their wishes. In the next section, we seek to answer the question whether advance directives can indeed lead to reductions in the costs of care and under what conditions such a use of advance directives can be justified.

\subsection{Medicalization of Old Age}

The elderly nowadays receive care that was unimaginable two or three decades ago. Owing to new technological developments, the elderly are treated at an increasing age with sophisticated medical technologies for acute medical conditions. Since the early 1990s, the number of people aged over 80 or even 90 receiving open heart surgery, organ transplantation or renal dialysis has increased sharply (Natarajan et al. 2007; Turrentine et al. 2006). Though such treatments can be beneficial and enhance quality of life, some of these technologies are less successful. This is particularly true of intensive care technology, which is increasingly accessed by old and very old patients. A study by Bagshaw et al. (2009) in intensive care units (ICUs) in Australia and New Zealand found out that the proportion of patients aged over 80 was rapidly increasing. However, age $\geq 80$ years was associated with higher ICU and hospital death compared with younger age strata. Factors associated with lower survival rates included admission from a chronic care facility, comorbidity, non-surgical admission and longer stay in the ICU. Patients 
who survived $(80 \%)$ usually did not return home but were discharged to nursing home care or other long-term care facilities. A study by Roch et al. (2011) on survival factors for 299 patients aged 80 years or over admitted to intensive care between 2001 and 2006 found that hospital mortality was $55 \%$. Up to $50 \%$ of the patients discharged from hospital were still alive at 2 years, but mortality was three times higher than for the general population. Mortality was particularly high among patients with severe acute disease at admission and also after discharge.

Quality of life after discharge to a nursing home is often much lower than for the reference population. Cuthbertson et al. (2010) followed 300 patients with median age $>60$ for a period of five years after ICU discharge. They found that ICU admission is associated with high mortality, poor physical quality of life and low quality-adjusted life years gained compared to the general population. In a study of one-year trajectories after ICU discharge, Unroe et al. (2010) found that patients with a poor outcome were older, had more comorbid conditions and were more frequently discharged while still receiving mechanical ventilation than those with better outcomes. They were particularly concerned about patients with intermediate outcomes, i.e. those who are alive but have moderate functional dependency. These previously high-functioning patients rarely improved over time; instead, they were cycling frequently between post-acute care facilities and hospitals. The authors argued that prolonged mechanical ventilation is a highly resource-intensive condition with a generally poor outcome. Given the disproportionately high costs and profound disability associated with prolonged mechanical ventilation, the authors advised clinicians to reconsider their approach to its provision. They also recommended that physicians should not only discuss long-term outcomes with surrogates in terms that they can easily understand but also explicitly convey the probable burdens of treatment and the likelihood of future functional dependency.

In elderly patients, prolonged mechanical ventilation and use of other intensive care technologies can be signs of overtreatment. According to Jennett (1995), patients of all ages are frequently overtreated, particularly those who present with critical illness, requiring emergency surgery, resuscitation or intensive care. Jennett observes that the most common reason for overtreatment is ignorance about the probability of benefit for a patient of a particular age and severity of illness. This is particularly true for the elderly because there is not much evidence about their response to critical care, as they are often excluded from clinical trials. But even if data are available, treatment decisions are often influenced by pressures from colleagues, nurses or relatives who expect interventions to be performed or who are keen to do anything to save the life of a beloved family member. Such a situation may lead to a cascade of treatments which is difficult to stop and which may result in substantial costs. The case reported by Lisa Krieger (2012), who witnessed the death of her father, is an illustration of such a process. It is summarized in an interview with Krieger conducted by Daniel Callahan (2012):

As Krieger put it, "The medical nightmare started, as they so often do, incrementally." While her father had made clear prior to his dementia that he wanted to die a "natural death," what he got ... was an unnatural "death by medicine," as someone once put it. The 
total cost for the hospital stay alone was $\$ 323,000$. Again and again Krieger had to make a decision about going on, as one crisis after another surfaced. With each new crisis, the doctors offered hope. There was, they said, "a decent chance we could turn it around." They could not, and he finally died. But as the days moved along from one crisis after another, Krieger kept asking herself, Was it all worth it? "Should we have quit?" she wrote. And when?

\subsection{Modern Medicine at the End of Life}

The case of Lisa Krieger's father must be situated in the context of the US, where there are many financial and professional incentives for physicians to continue with aggressive but expensive treatments. Instead of accepting that death will come sooner or later, many physicians do not give up the fight to add a few days or months to the life of dying patients - even when, like Lisa's father, they have advance directives in place.

In his book Setting Limits. Medical Goals in an Aging Society, Daniel Callahan (1987) argues that we should set limits to the use of expensive medical technology which extends the lives of elderly people for only a few weeks or months. Instead of extending life, medicine should put more efforts into enhancing life: human beings are going to die sometime, in spite of all efforts to extend life. Life cannot be extended indefinitely: this is not possible, nor is it desirable, as a longer life will result in worsening health. In this book, Callahan proposes that intensive medical treatment for the elderly be limited, making such treatments more available for the young, in order to increase their chances of reaching old age. According to Callahan, we all have the moral intuition that to die young is a tragedy, but that to die at an old age is "only a sadness". People who die young have not had the chance to realize their opportunities; their lives are ended prematurely. On the other hand, old people have had enough opportunities to lead a meaningful life. Their death might be more "tolerable", than the death of a young person. According to Callahan, most of us would opt for a greater chance to reach old age or, what he calls a "natural life span", which is not biological, but biographical. It is the period in which we have had the opportunity to realize our potential, whereupon death is a sad, but not tragic, event. After this natural life span has been reached, at age 75 or 80 , life-extending therapies (which are financed by society) should be limited. This proposal ought to be put into practice on the strict condition that the elderly will be offered improved access to long-term care. Limits to "acute care" must go hand in hand with more and better "comfort care".

Callahan's proposal has been strongly criticized as a kind of "ageist" discrimination (Barry and Bradley 1991; Binstock and Post 1991). Gerontologists and liberal ethicists, in particular, have argued that every age has its own aims and that nobody can determine for another whether their life is completed or their "natural life span" has been reached. There is no reason, they argue, why an old person should value his or her life less than a younger one. When one considers only 
years of life instead of life itself, one shows no respect for the unique value of the human person, which is the moral basis for our society.

Although Callahan's proposal for a compulsory age limit for (publicly funded) acute medical care is difficult to accept for various (ethical, social and political) reasons, his concerns about the uncritical or unthinking application of lifeextending care to vulnerable and dying elderly people are still valid. In his book Taming the Beloved Beast (Callahan 2009), he criticizes the Medicare system for rewarding the tendency to pay for continuously increasing costs for diminishing returns in terms of life expectancy. Not only is this development putting the health and social care system in jeopardy, it is not even in the interests of many elderly people who might be better off with palliative care than with aggressive and highly burdensome intensive care technologies.

\subsection{Can Advance Directives Help to Cut Costs?}

But if age limits are a "no-go", can advance directives help to cut costs while, at the same time, promoting more appropriate care at the end of life? Many elderly patients seem to prefer medical interventions to be limited at the end of life, and instead would like to receive comfort care and palliative treatments (McCarthy et al. 2008). Advance directives to limit aggressive life-extending care would then have the combined result of ensuring comfort care and reducing costs-at least for those who refuse excessive end-of-life treatment.

Since the end of the 1990s, various studies have been conducted to find out whether advance directives indeed result in diminishing costs of care. The first major effort to investigate this question was the US Study to Understand Prognoses and Preferences for Outcomes and Risks of Treatments (The SUPPORT Principal Investigators 1995), which involved 9,105 seriously ill patients. SUPPORT included an observational study (phase I) and a randomized trial with an intervention and a control arm (phase II). The trial aimed to determine whether providing physicians with information about patient prognosis and patient preferences for end-of-life care would have an impact on the use of intensive care units and other hospital resources. The control arm of the study received no specific interventions relating to patient preferences. The intervention arm sought to address physicians' lack of knowledge of patient preferences by giving them information on prognoses and on patient preferences. The intervention also included the involvement of nurses to elicit such preferences and to facilitate advance care planning and enable palliative care. The first part of the study (phase I) documented a wide range of shortcomings in the care provided for seriously ill people. However, the intervention part of the study (phase II) showed that the eliciting and documenting of patient preferences, and communication of this information to physicians, had no impact on the use of hospital resources as compared to the control arm of the study. For example, for the 680 intervention patients who died in hospital, the number of days spent in an ICU, comatose or receiving mechanical ventilation be- 
fore death, was the same as for the 530 control patients. The authors concluded that:

The study certainly casts a pall over any claim that, if the health care system is given additional resources for collaborative decision-making in the form of skilled professional time, improvements will occur.

A systematic review by Taylor et al. (1999) of primary studies assessing the association between advance directives and resource use found little evidence to support the hypothesis that advance directives reduce the use of resources by hospitalized patients. Some retrospective studies have shown savings, but these studies had methodological shortcomings. Prospective studies with experimental methods, such as the SUPPORT study, have yielded no evidence of cost savings with the use of advance directives.

Though most studies have failed to provide significant evidence of advance directives contributing to reduced resource use or cost control, a recent study by Nicholas et al. (2011) provided a new perspective by looking into regional differences. The authors argued that advance directives can only influence treatment decisions when the patient's wishes are inconsistent with what would be provided if there was no advance directive. They hypothesized that advance directives would have the greatest limiting impact on medical care in regions where the norm is to provide high-level intensive medical interventions at the end of life. They found that advance directives were more common in areas where there were already lower levels of healthcare spending at the end of life. Advance directives had no direct effect on resource use in these areas. However, in areas with high levels of spending on end-of-life care, advance directives had much more impact on hospital use and were associated with a lower likelihood of in-hospital death.

The authors conclude that the clinical impact of advance directives is highly dependent on the regional context in which a patient receives care. They argue that advance directives are important to ensure care consistent with patient preferences in areas where aggressive end-of-life treatment is provided. In areas that already have a lower intensity of care, advance directives will likely have less impact. These findings may explain the sometimes conflicting evidence of the impact of advance directives on end-of-life healthcare expenditures.

Zhang et al. (2009) concluded that increasing communication between patients and their physicians is associated with better outcomes and less expensive care. In this study, 627 advanced cancer patients were interviewed at baseline and followed up through death. Patients were asked specific questions about individual treatment preferences, particularly with regard to end-of-life care. The costs for ICU and hospital stays, hospice care and life-sustaining procedures received in the last week of life were aggregated. Patients who reported having end-of-life conversations with their physicians were less likely to undergo ventilation or resuscitation, or to be admitted to or die in an ICU. They were more likely to receive outpatient hospice care and to stay longer in the hospice. They were in less physical distress than patients without such conversations. The aggregate costs of treatment were $35.7 \%$ lower than for patients without end-of-life discussions. According to 
Zhang et al., additional analysis showed that higher medical costs in the final week of life were associated with more physical distress in the last week of life and worse overall quality of death as reported by the caregiver.

\subsection{Advance Directives and Patient Autonomy}

In view of the ever-increasing costs of end-of-life care, there is a serious risk of resources being drawn away from, for example, life-enhancing, chronic or longterm care. The costs of the use of high technology in the final stages of life need to be reduced in order to preserve the right balance of health and social care services, and equitable access to these services. Moreover, intensive care at the end of life is often not effective and not wanted by patients (McCarthy et al. 2008). If advance directives can help to control the costs of care, there are sufficient ethical arguments in favour of their being used for this purpose. However, the evidence about the impact of advance directives on costs is not conclusive. Conversations between physicians and patients, or advance care planning (ACP), seem to be a more effective way to reduce costs, as shown in the study by Zhang et al. (2009).

Advance directives or ACP can only be used to reduce costs if they indeed reflect patients' wishes. Otherwise, they might become blunt rationing instruments to reduce access to services for older people. The ethical debate about advance directives points up various problems relating to their supposed role in enhancing or extending patient autonomy.

One of the main problems associated with advance directives is the question of whether they can express the genuine will of a person in a particular situation. With reference to Buchanan and Brock (1990: 90), who discuss whether it is possible "to view the rights of incompetent individuals as an extension of the rights of competent individuals", Davis (2009) distinguishes between what he calls "Extension View" arguments and those which question the moral authority of advance directives. Dworkin (1993: 224), defending the Extension View, argues for example that past preferences should always be respected because of the individual's "right to a life structured by his own values", even if these preferences conflict with the incompetent individual's best interests or (assumed) present wishes. Taking the case of a patient with Alzheimer's disease who formerly stated in an advance directive that she would not want to receive treatments in order to be kept alive in such a condition but now seems to be happy with her life, Dworkin distinguishes between experiential interests (quality of life, pleasure, contentment, lack of pain) and critical interests (value judgements, basic autonomous decisions). $\mathrm{He}$ comes to the conclusion that the latter-determined by the capable individual in accordance with her basic attitude towards life-are more important than the present experiential interests of the incapacitated individual (Dworkin, 1993: 201202). Therefore, the refusal of treatment specified in an advance directive by a person with Alzheimer's disease should be respected, regardless of her currently experienced happiness. Similarly, Buchanan (1988) argues that despite the loss of 
psychological continuity, personal identity is preserved. Accordingly, advance directives retain their full moral force unless neurological damage is so severe that the living being that remains is not a person any more and has thus no personal identity. Opposing this perspective, Dresser (1994) adopts a critical view of the moral authority of wishes expressed in advance because the competent person may not always be fully informed at the time a decision concerning future treatment is made. In addition, following Parfit (1984), who claims that identity can be reduced to psychological continuity, Dresser (1986) argues that personal identity does not remain the same throughout a life but develops continually, depending on various external and psychological factors. According to her view, an advance directive does not unconditionally express the authentic will of a person in a concrete situation. This argument is backed up by studies which show that preferences for life-sustaining treatment are indeed dependent on the context in which they are made, and that individuals may express different treatment preferences when they are healthy than when they are ill (Ditto et al. 2006).

The difficulty of assessing the authenticity of previously expressed wishes and thus the moral authority of an advance directive surfaces not only in the philosophical but also in the legal debate (Maclean 2006). Whereas countries with a strong emphasis on patient autonomy, such as England, recognize the binding force of advance directives (Horn 2012; Huxtable 2012), specific requirements have to be met so that a directive can be validated. Some authors object that advance directives can in fact be too easily invalidated (Michalowski 2005).

Finally, it appears that advance directives are rarely encountered in practice, and authors such as Fagerlin and Schneider (2004) who first considered that ADs "serve a strong version of patients' autonomy" come to the conclusion "that living wills do not and cannot achieve that goal". According to these authors, the reasons for this failure are that only few people actually write an advance directive, know what they really want and can articulate their wishes; others are afraid of misinterpretations, or that their living wills will not be taken into consideration.

Given the increasing complexity of medical technologies, how can a patient, particularly an elder person, decide what treatment she wants or does not want to receive once she is incompetent? And how can physicians who have to validate and apply an advance directive be certain that they are acting in accordance with the author's genuine wishes?

To address the moral and practical questions surrounding the use of advance directives, a number of authors (Messinger-Rapport et al. 2009; Halliday 2009; Ozanne et al. 2009) suggest that full and frank physician-patient communication could enable both the physician to better assess the validity of an advance directive and the patient to better express her wishes and preferences.

Studies from the US (e.g. Hammes et al. 2010) show that physician-patient communication on treatment preferences towards the end of life is significantly improved by the use of so-called POLST (Physician Orders for Life-Sustaining Treatments), also known as MOLST/COLST (Medical/Clinician Orders for LifeSustaining Treatments). These orders, used in more than half of US states (Hickman et al. 2010), have to be completed by the physician together with the patient 
and/or surrogates and are legally valid medical decisions, which have to be respected when the patient is no longer able to express her wishes. Contrary to advance directives, which can be completed by any (sick or healthy) adult, POLST are employed as a complement to advance directives only for seriously or terminally ill patients. Yet, considering the fact that advance directives are completed mainly by seriously or terminally ill patients (Virmani et al. 1994; Heffner et al. 1996), and that advance directives are often not accessible or wishes are not clearly defined, one could even think of POLST replacing rather than merely complementing advance directives.

Before advance directives are used in the context of cost control, concerns regarding the authenticity of these directives should be taken into account and ACP should take place in a broader sense, in the form of good physician-patient communication about the patient's general but also specific preferences. Such communication could be facilitated by the use of standardized forms such as POLST (Emanuel 2000).

\subsection{Conclusion}

High-tech, intensive end-of-life care for the elderly leads to increased costs without always improving patients' well-being or corresponding to elderly patients' preferences. In some cases, as we have shown, costly high-tech medical care may even impair the patient's physical and psychological condition. Yet setting limits to intensive medical treatment appears to be difficult for physicians, whose priority is most often to save lives, rather than withdrawing treatment. In order to address these problems, advance directives refusing treatment have been discussed as a means of helping to reduce costs associated with overtreatment or unwanted treatment and thus to better adapt resource use to individual needs and preferences, even when a patient is no longer able to communicate her wishes. Yet there is only conflicting evidence that these directives could have an impact on resource allocation, as physicians seem to be reluctant to respect patients' previously expressed treatment refusals, particularly when such wishes do not accord with the physicians' opinion. These findings must be put in the context of ethical, legal and practical problems regarding the validity and applicability of advance directives. We have argued that the use of advance directives for cost control is only justified if they reflect patients' authentic wishes. However, as discussed above, important questions can be raised as to whether advance directives are valid instruments to express the patient's genuine will in a specific situation and are thus ethically acceptable in the context of cost control and equitable allocation of resources. It is difficult for many patients to anticipate future events and specific preferences, and advance directives are not always known about or taken into account by physicians. Therefore, we argue that the writing of advance directives should not be left to the patient alone. Rather, they should be considered as tools for opening physician-patient communication about difficult issues and individual treatment prefer- 
ences with regard to end-of-life care. If advance directives were placed in the broader context of ACP, aiming to enhance conversations between physicians and patients, this could be, as pointed out by Zhang et al. (2009), a way forward to increase patient autonomy and reduce the costs associated with questionable end-oflife care.

\section{References}

Bagshaw, Sean M., Steve A.R. Webb, Anthony Delaney, Carol George, David Pilcher, Graeme K Hart, and Rinaldo Bellomo. 2009. "Very old patients admitted to intensive care in Australia and New Zealand: a multi-centre cohort analysis." Crit Care 13(2): R45.

Barry, Robert L., and Gerard V. Bradley (eds) 1991. Set No Limits: A Rebuttal to Daniel Callahan's Proposal to Limit Health Care for the Elderly. Urbana: University of Illinois Press.

Binstock, Robert H. and Stephen G. Post. 1991. Too Old for Health Care? Controversies in Medicine, Law, Economics, and Ethics. Baltimore: The Johns Hopkins University Press.

Buchanan, Allen E. 1988. "Advance Directives and the Personal Identity Problem". Philosophy and Public Affairs 17(4): 277-302.

Buchanan, Allen E. and Dan W. Brock. 1990. Deciding for others: the ethics of surrogate decision-making. New York: Cambridge University Press.

Callahan, Daniel. 1987. Setting Limits. Medical Goals in an Aging Society. New York:Touchstone.

Callahan, Daniel. 2009. Taming the Beloved Beast: How Medical Technology Costs Are Destroying Our Health Care System. Princeton: Princeton University Press.

Callahan, Daniel. 2012. "The Trial of "Death by Medicine": An Interview with Lisa Krieger." Health Care Cost Monitor. The Hasting Center.

http://healthcarecostmonitor.thehastingscenter.org/daniel-callahan/the-trial-of-

$\%$ E2\%80\%9Cdeath-by-medicine $\%$ E2\%80\%9D-an-interview-with-lisa-krieger/. Accessed 19 July 2012.

Cuthbertson, Brian H., Siân Roughton, David Jenkinson, Graeme MacLennan, and Luke Vale. 2010. "Quality of life in the five years after intensive care: a cohort study". Crit Care 14(1): R6.

Davis, John K. 2009. "Precedent Autonomy, Advance Directives and End-of-Life Care". In The Oxford Handbook of Bioethics, ed. Bonnie Steinbock. 349-374. New York:Oxford University Press.

Ditto, Peter H., Jill A. Jacobson, William D.Smucker, Joseph H.Danks, and Angela Fagerlin. 2006. "Context changes choices: a prospective study of the effects of hospitalization on lifesustaining treatment preferences". MDM 26(4): 313-22.

Dixon, Tracey, Mary Shaw, Stephen Frankel, and Shah Ebrahim. 2004. "Hospital admissions, age, and death: retrospective cohort study". BMJ 29(7451): 1288.

Dresser, Rebecca. 1986. "Life, Death, and Incompetent Patients: Conceptual Infirmities and Hidden Values in the Law". Ariz Law Rev 28 (3): 379.

Dresser, Rebecca. 1994. "Missing Persons: Legal Perceptions of Incompetent Patients". Rutgers Law Rev 46: 624-630.

Dworkin, Ronald. 1993. Life's Dominion: An Argument About Abortion, Euthanasia, and Individual Freedom. New York: Alfred A. Knopf.

Emanuel, Linda. 2000. "Living wills can help doctors and patients talk about dying". BMJ 320: 1618-1619.

Fagerlin, Angela and Carl E. Schneider. 2004. "Enough: The Failure of the Living Will". Hastings Center Report 34: 30-42

Fassbender. Konrad, Robin L. Fainsinger, Mary Carson, and Barry A. Finegan. 2009. "Cost Trajectories at the End of Life: The Canadian Experience". J pain symptom manage 38(1):75-80.

Halliday, Samantha. 2009. "Advance Decisions and the Mental Capacity Act". BJN 18 (11): 697699.

Hammes, Bernard J., Brenda L. Rooney, and Jacob D. Gundrum. 2010. “A Comparative, Retrospective, Observational Study of the Prevalence, Availability, and Specificity of Advance 
Care Plans in a County that Implemented an Advance Care Planning Microsystem”. Journal of the American Geriatrics Society 58: 1249-1255, doi:10.1111/j.1532-5415.2010.02956.x.

Heffner, John E., Bonnie Fahy, Lana Hilling, and Celia Barbieri .1996. "Attitudes regarding advance directives among patients in pulmonary rehabilitation". American Journal of Respiratory and Critical Care Medicine 154 (6): 1735-1740.

Hickman, Susan E., Christine A. Nelson, Nancy A. Perrin, Alvin H. Moss, Bernard J. Hammes, and Susan W. Tolle. 2010. "A Comparison of Methods to Communicate Treatment Preferences in Nursing Facilities: Traditional Practices Versus the physician Orders for LifeSustaining Treatment Program". Journal of the American Geriatric Society 58: 1241-1248.

Horn, Ruth. 2012. "Advance directives in England and France: Different Concepts, Different Values, Different Societies." Health Care Analysis. doi: 10.1007/s10728-012-0210-7.

Huxtable, Richard. 2012. Law, Ethics and Compromise at the Limits of Life: To Treat or Not to Treat? London: Routledge-Cavendish.

Jennett, Bryan. 1995. "The Elderly and High-Technology Therapies". In A World Growing Old. The Coming Health Care Challenges, ed. Daniel Callahan, Ruud ter Meulen, and Eva Topinkova, 85-96. Washington: Georgetown University Press.

Jones. Charles I. 2002. "Why have health care expenditures as a share of GDP risen so much. Working Paper 9325". Cambridge MA: National Bureau of Economic Research.

Krieger, Lisa. 2012. "The cost of dying: It's hard to reject care even as costs soar". Mercury News. http://www.mercurynews.com/cost-of-dying/ci_19898736. Accessed 19 July 2012.

Lubitz, James D. and Gerald F. Riley. 1993. "Trends in Medicare Payments in the Last Year of Life”. N Engl J Med 328:1092-1096.

Maclean, Alasdair R. 2006. "Advance directives, future selves and decision-making”. Medical Law Review 14: 291-320.

McCarthy, Ellen, Michael Pencina, Margaret Kelly-Hayes, Jane Evans, Elizabeth Oberacker, Ralph D'Agostino, Risa Burns, and Joanne Murabito. 2008. "Advance Care Planning and Health Care Preferences of Community-Dwelling Elders: The Framingham Heart Study." $J$ Gerontol A Biol Sci Med Sci 63(9): 951-959.

McGrail K, Green B, Barer ML, Evans RG, Hertzman C, and Normand C. 2000. "Age, costs of acute and long-term care and proximity to death: evidence for 1987-88 and 1994-95 in British Columbia”. Age Ageing 29(3): 249-53.

Messinger-Rapport, Barbara J., Elizabeth E. Baum, and Martin L. Smith. 2009. "Advance Care Planning: Beyond the Living Will”. CCJM 76 (5): 287-8.

Michalowski, Sabine. 2005. "Advance Refusals of Life-Sustaining Medical Treatment: The Relativity of an Absolute Right”. The Modern Law Review 68: 958-982.

Miller, Susan C., Orna Intrator, Pedro Gozalo, Jason Roy, Janet Barber, and Vincent Mor. 2004 "Government expenditures at the end of life for short- and long-stay nursing home residents: differences by hospice enrollment status". J Am Geriatr Soc 52(8):1284-92.

Natarajan, Arun, Samad Samadian, and Stephen Clark. 2007. "Coronary artery bypass surgery in elderly people". Postgrad Med J 83(977): 154-158.

Newhouse, Joseph. 1992. "Medical care costs: how much welfare loss". Journal of Economic Perspectives 6:3-21.

Nicholas, Lauren H., Kenneth M. Langa, Theodore J. Iwashyna, and David R. Weir. 2011. "Regional Variation in the Association Between Advance Directives and End-of-Life Medicare Expenditure". JAMA 306(13): 1447-1453.

Ozanne, Elissa M., Ann Partridge, Beverly Moy, Katherine J. Ellis, and Karen R. Sepucha. 2009. "Doctor-Patient Communication about Advance Directives in Metastatic Breast Cancer". $J$ Palliat Med 12 (6): 547-53.

Parfit, Derek. 1984. Reasons and Persons. Oxford: Clarendon Press.

Roch, Antoine, Sandrine Wiramus, Vanessa Pauly, Jean-Marie Forel, Christophe Guervilly, Marc Gainnier, and Laurent Papazian. 2011. "Long-term outcome in medical patients aged 80 or over following admission to an intensive care unit". Crit Care;15(1):R36.

Taylor JS, Heyland DK, and Taylor SJ. 1999. "How advance directives affect hospital resource use. Systematic review of the literature". Can Fam Physician 45: 2408-2413. 
The SUPPORT Principal Investigators. 1995. "A Controlled Trial to Improve Care for Seriously Ill Hospitalized Patients. The Study to Understand Prognoses and Preferences for Outcomes and Risks of Treatments (SUPPORT)". JAMA, 274(20), 1596.

Turrentine, Florence E., Hongkun Wang, Virginia B. Simpson, and R. Scott Jones. 2006. "Surgical Risk Factors, Morbidity, and Mortality in Elderly Patients". JACS 203 (6): 865-877.

Unroe, Mark, Jeremy M.Kahn, Shannon S. Carson, Joseph A. Govert, Tereza Martinu, J. Shailaja, Alison S. Sathy, Jessica Clay, Alice Chia, James A. Gray, Christopher E. Tulsky, Cox. 2010. "One-year trajectories of care and resource utilization for recipients of prolonged mechanical ventilation: a cohort study". Ann Intern Med 153(3):167-175.

Virmani, Jaya, Lawrence J. Schneiderman, and Robert M. Kaplan. 1994. "Relationship of advance directives to physician-patient communication". Archives of Internal Medicine 154(8): 909-913;

Yang, Zhou, Edward C. Norton, and Sally C. Stearns. 2003. "Longevity and health care expenditures: the real reasons older people spend more". J Gerontol B Psychol Sci Soc Sci 58(1): S210 .

Zhang, Baohui, Alexi A. Wright, Haiden A. Huskamp, Matthew E. Nilsson, Matthew L. Maciejewski, Craig C. Earle, Susan D. Block, Paul K. Maciejewski, and Holly G. Prigerson. 2009. "Health Care Costs in the Last Week of Life: Associations with End of Life Conversations". Arch Intern Med 9; 169(5): 480-488.

Zweifel, Peter, Stefan Felder, and Markus Meiers. 1999. "Ageing of population and health care expenditure: a red herring?" Health Econ. 8(6): 485-496. 